\title{
Determination of the Transport Properties of Structural Concrete Using AC Impedance Spectroscopy Techniques
}

\author{
Lipeng Wu, Peng Dai, and Yong Li \\ School of Civil Engineering, Shijiazhuang Tiedao University, Shijiazhuang 050043, China \\ Correspondence should be addressed to Lipeng Wu; lipengwu@outlook.com
}

Received 11 July 2016; Accepted 5 October 2016

Academic Editor: Song Han

Copyright (C) 2016 Lipeng Wu et al. This is an open access article distributed under the Creative Commons Attribution License, which permits unrestricted use, distribution, and reproduction in any medium, provided the original work is properly cited.

\begin{abstract}
All over the world, particularly in severe environmental conditions, there are reinforced concrete structures that develop nonnegligible phenomena of durability problems. Most of the durability problems are related to hazardous substances invasion. Both engineering practice and scientific studies have revealed that the transport property of near-surface concrete is a main factor in the durability of concrete structures. Among many transport parameters, the chloride ion diffusion coefficient is the most important one, which provides important information on material design and service life prediction. In this paper, AC impedance spectroscopy technology was employed in the measurement of chloride ion diffusion coefficient. The relationship between mesostructure parameters and chloride ion diffusion coefficient was deduced by introducing a reasonable equivalent circuit model. Taking into account the conductivity difference caused by various cementitious material systems, the diffusion coefficient can be corrected, and a diffusion coefficient determination method based on AC impedance spectroscopy technique was established. For the convenience of application, a relationship between the newly proposed method and a widely recognized standard method was obtained. The proposed method can be applied to laboratory testing and establishes the theoretical basis for field tests.
\end{abstract}

\section{Introduction}

Durability of concrete structures is one of the unsolved problems in the field of civil engineering and is an international research concern [1]. Durability problems are largely caused by the intrusion of external hazardous substances, which means that the transport property of near-surface concrete is an important aspect that affects durability [2]. A generally accepted fact is that transport property is essentially determined by the mesostructure.

Concrete is a typical porous material. Its pore system includes C-S-H gel pores, capillary pores, microcracks, and micropores. Many ions, such as $\mathrm{Ca}^{2+}, \mathrm{Na}^{+}, \mathrm{K}^{+}, \mathrm{OH}^{-}, \mathrm{Cl}^{-}$, and $\mathrm{SO}_{4}{ }^{2-}$, exist, which constitute a complex dynamic electrochemical system. Under AC excitation, the system exhibits a characteristic of a resistor-capacitor combination, and the mesostructure can be studied by using AC impedance spectroscopy.

To separate the desired mesostructure parameters from measured impedance data, researchers have proposed a number of equivalent circuit models [3-8]. Some model parameters can be obtained through numerical fitting by using measured data and a preset equivalent circuit model. These parameters can be used as quantitative characterization of the mesostructure and hydration degree of cement-based material.

\section{Concrete Mesostructure and Equivalent Circuit Model}

The selected scale should not be small when considering the role of pores in ion diffusion. The C-S-H gel pore does not contribute to permeability. Therefore, only the capillary pores and the pores between C-S-H gels were considered. Basically, three conduction pathways exist for alternating current in concrete, that is, continuous conduction, discontinuous conduction, and the so-called "insulating" conduction paths. The continuous conduction path is a series of connected capillary pores or connected microcracks. If the pore connectivity is cut off by cementitious material or its hydration products, the discontinuous conduction path 


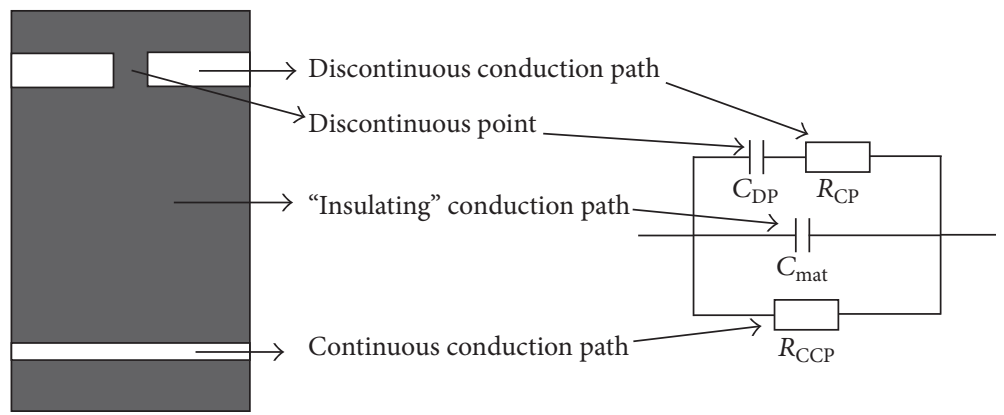

Figure 1: Concrete mesostructure for AC conducting.

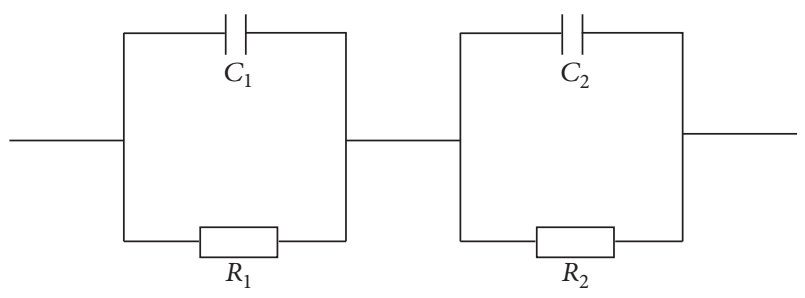

FIgURE 2: Converted equivalent circuit.

is formed. In addition to continuous and discontinuous conduction paths, isolated cementitious material particles and their hydration products or even the entire solid concrete block can also be conductive for alternating current. Based on the above considerations, the concrete mesostructure for AC conducting can be described in Figure 1.

The equivalent circuit model that corresponds to Figure 1 can be expressed as

$$
\frac{1}{Z}=\frac{1}{Z_{1}}+\frac{1}{Z_{2}}+\frac{1}{Z_{3}},
$$

where $Z_{1}$ is the impedance of the "insulating" conduction path, $Z_{1}=1 /\left(j \omega C_{\text {mat }}\right)$, and $C_{\text {mat }}$ is the capacitance of the test block; $Z_{2}$ is the impedance of the discontinuous conduction path, that is, the sum of the capacitance of the discontinuous point and the resistance of the cut-off continuous conduction path, $Z_{2}=R_{\mathrm{CP}}+1 /\left(j \omega C_{\mathrm{DP}}\right), R_{\mathrm{CP}}$ is the resistance of the cutoff continuous conduction path, and $C_{D P}$ is the capacitance of discontinuous point; and $Z_{3}$ is the resistance of continuous conduction path, $Z_{3}=R_{\mathrm{CCP}}$.

According to basic circuit theory, the equivalent circuit described in (1) can be converted to a circuit shown in Figure 2.

The conversion relationship of the two equivalent circuits is shown in

$$
\begin{aligned}
R_{\mathrm{CP}} & =\left(R_{0}+R_{1}\right) \frac{R_{0}}{R_{1}}, \\
R_{\mathrm{CCP}} & =R_{0}+R_{1}, \\
C_{\mathrm{DP}} & =\left(C_{0}+C_{1}\right)\left(\frac{R_{1}}{R_{0}+R_{1}}\right)^{2}, \\
C_{\text {mat }} & =\frac{C_{0} C_{1}}{C_{0}+C_{1}} .
\end{aligned}
$$

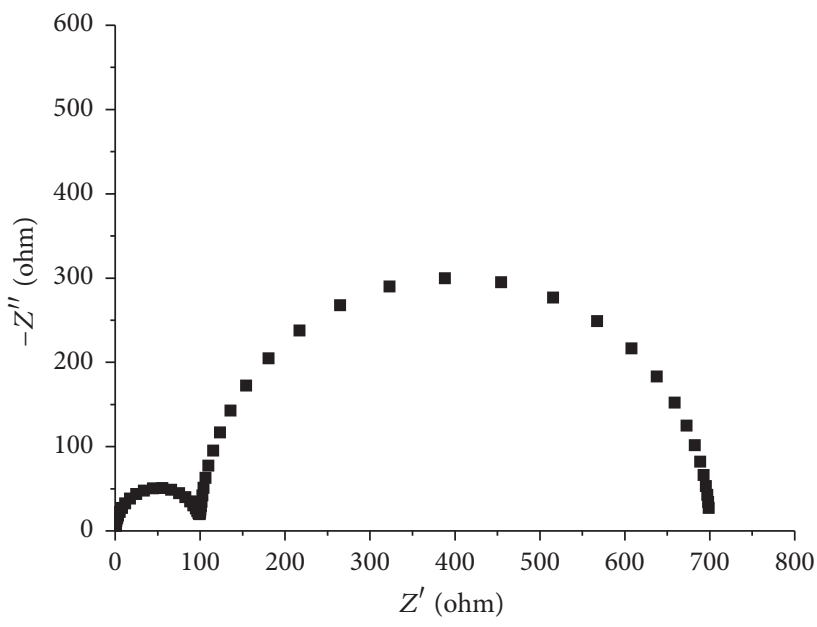

FIgUre 3: Nyquist plot of the equivalent circuit model shown in Figure 2.

A parallel combination of a capacitor and a resistor produces a semicircle in the Nyquist plot. Therefore, two semicircles should appear on the plot of the equivalent circuit shown in Figure 2. Figure 3 shows the relationship between the resistance parameters and the location and size of the semicircles.

Taking into account the second equation in (2), the resistance of the continuous conduction path is the intersection point of the right semicircle with the real axis. However, the Nyquist plot of the measured impedance of cementbased materials does not have two semicircles, but often, only a semicircle appears. Figure 4 is a typical Nyquist plot of concrete; the concrete composition was $23.3 \mathrm{Kg}$ silica fume, $442.7 \mathrm{Kg}$ normal Portland cement, $750 \mathrm{Kg}$ sand, $1125 \mathrm{Kg}$ gravel, $186.4 \mathrm{Kg}$ water, so $w / b=0.4$; the test age is $28 \mathrm{~d}$.

The left arc does not occur, which indicates that $C_{0}$ is much less than $C_{1}$. Thus, the diameter of the left arc is very small with respect to the right arc, and therefore, the left arc is not visible; Cabeza et al. [3, 7] proved this point. Thus, the equivalent circuit can be further simplified as shown in Figure 5, which also shows the corresponding Nyquist plot.

The above discussion indicates that $R_{\mathrm{CCP}}$, which is the parameter that characterizes the interconnecting porosity that is most relevant to permeability, can be linked with measured impedance spectroscopy. 


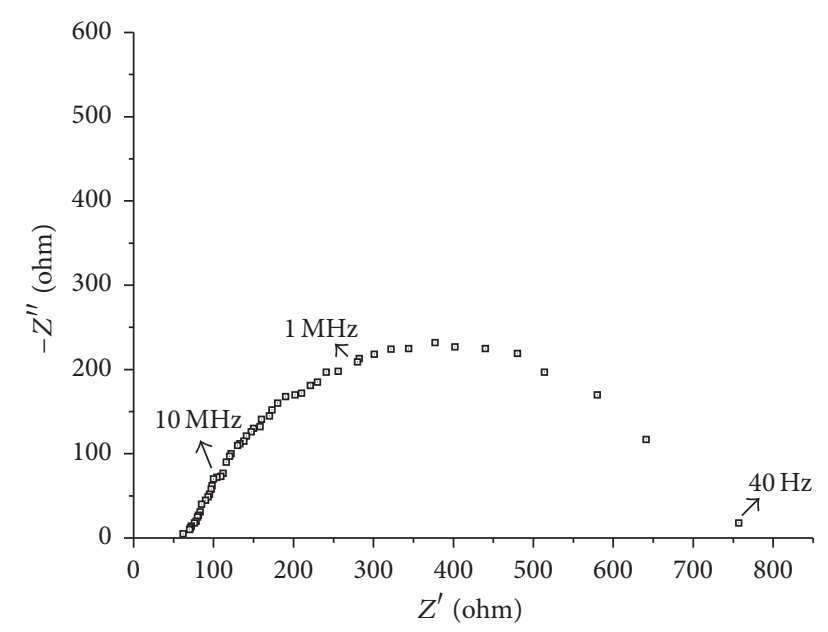

FIgURE 4: High-frequency range Nyquist plot of typical concrete.

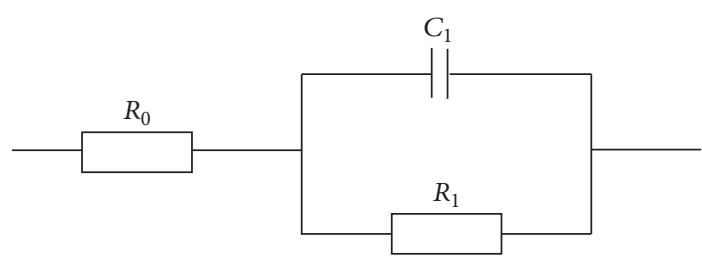

(a) Further simplified equivalent circuit

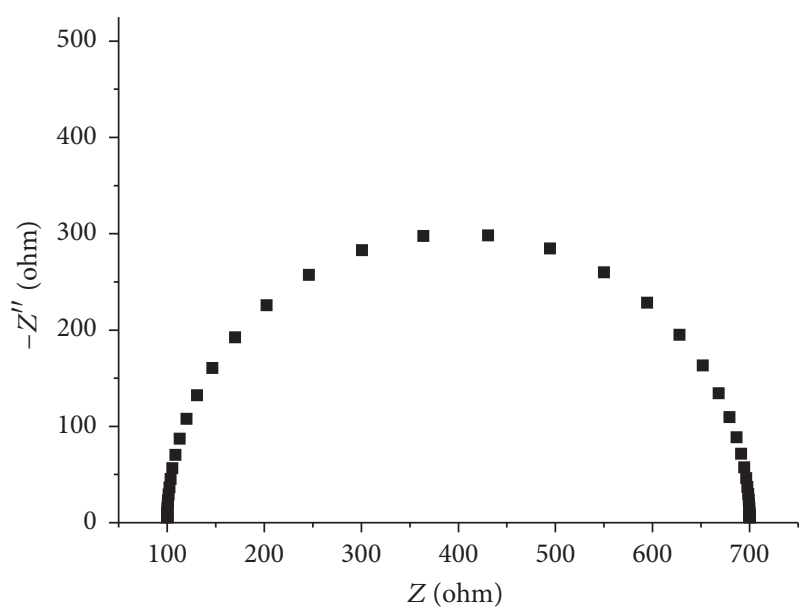

(b) Corresponding Nyquist plot of the simplified equivalent circuit

FIGURE 5: Further simplified equivalent circuit and its Nyquist plot.

\section{Relationship between AC Impedance Parameters and Permeability}

The relationship between AC impedance parameters and permeability can be established in two ways. An empirical relationship between the two can be mathematically regressed by conducting a large number of experiments. However, the disadvantage of this approach is the lack of reliable theoretical basis. Another way to derive some kind of quantitative relationship between the two is through theoretical derivation. This paper adopted the latter approach.
Einstein and Smoluchowski presented an equation on the diffusion of charged particles in solution in 1905 and 1906, respectively; this equation is known as the EinsteinSmoluchowski equation [9], which is shown as follows:

$$
D_{q}=\frac{\mu_{q} k_{B} T}{q},
$$

where $\mu_{q}$ is the ion mobility $\left(\mathrm{m}^{2} /(\mathrm{V} \cdot \mathrm{s})\right) ; k_{B}$ is the Boltzmann constant $\left(1.38 \cdot 10^{-23} \mathrm{~J} / \mathrm{K}\right) ; q$ is the charge carried by ions (C); and $T$ is the absolute temperature $(\mathrm{K})$. Through the relationship among the Boltzmann constant, the Avogadro constant $\left(N_{A}\right)$, the Faraday constant $(F)$, the elementary electric charge $(e)$, and the universal gas constant $(R)$, that is, $k_{B}=R / N_{A}, F=e N_{A}$, and $q=z_{i} e$, where $z_{i}$ is the absolute value of valence, (4) was obtained:

$$
\mu_{q}=\frac{z_{q} F}{R T} D_{q}
$$

As for the most significant chloride ion diffusion coefficient $D_{\mathrm{Cl}^{-}}$, which is directly relevant to the durability of reinforced concrete structures, (4) can be specifically written as [9]

$$
D_{\mathrm{Cl}^{-}}=\frac{R T}{z_{\mathrm{Cl}^{-}} F} \mu_{\mathrm{Cl}^{-}}
$$

To use (5), a certain concentration of chloride solution must be introduced, and chloride ion mobility must be considered. In AC impedance spectroscopy testing, the measured resistance (or resistivity, conductivity) is a result of the joint action of various ions in a pore solution. To obtain the chloride ion diffusion coefficient, the contribution of chloride ions to the conductance needs to be separated from the total conductance. To achieve this, a $1 \mathrm{~mol} / \mathrm{L} \mathrm{NaCl}$ solution was used to saturate a concrete test block to weaken the influence of other existing ions. Thus, the conductivity expression, $\sigma=$ $F \sum z_{i} \mu_{i} C_{i}$, where $C_{i}$ is the concentration and $z_{i}$ is the activity coefficient $\left(z_{i}=1\right)$, can be written as

$$
\sigma=F *\left(\mu_{\mathrm{Cl}^{-}} C_{\mathrm{Cl}^{-}}+\mu_{\mathrm{Na}^{+}} C_{\mathrm{Na}^{+}}\right) .
$$

To further differentiate the contribution of chloride ions and sodium ions to the conductance, the contribution percentage of chloride ions is $61 \%$, which is close to that of an infinitely diluted sodium chloride solution (60.4\%), under the conditions of $25^{\circ} \mathrm{C}$ and $1 \mathrm{~mol} / \mathrm{L}$ concentration; this information was verified by consulting a chemistry handbook. Combining (5) and (6) obtains

$$
D_{\mathrm{Cl}^{-}}=\frac{\sigma R T}{1.64 F^{2} C_{\mathrm{Cl}^{-}}} \text {. }
$$

Taking into account the relationship between resistance $(\rho)$, conductivity $(\sigma)$, and cell constant $(a=l / A$, where $l$ is the thickness of the test block and $A$ is the contact area of the electrode and the test block), (8) is obtained:

$$
\sigma=\frac{1}{\rho}=\frac{a}{R_{\mathrm{CCP}}} .
$$


TABLE 1: Chemical compositions of cement and mineral admixtures (\% by weight).

\begin{tabular}{lccccccc}
\hline Composition & $\mathrm{SiO}_{2}$ & $\mathrm{Al}_{2} \mathrm{O}_{3}$ & $\mathrm{Fe}_{2} \mathrm{O}_{3}$ & $\mathrm{CaO}$ & $\mathrm{MgO}$ & $\mathrm{SO}_{3}$ & $\mathrm{Na}_{2} \mathrm{O}$ \\
\hline Cement & 21.09 & 4.34 & 2.81 & 62.5 & 1.81 & 2.87 & 0.15 \\
Slag & 34.55 & 14.36 & 0.45 & 33.94 & 11.16 & 1.95 & 0.28 \\
Fly ash & 57.57 & 21.91 & 7.72 & 3.87 & 1.68 & 0.41 & 0.35 \\
Silica fume & 92.63 & 1.05 & 1.17 & 0.34 & 0.73 & 0.30 & 0.22 \\
\hline
\end{tabular}

$w$ : mass fraction.

Therefore, the relationship between chloride ion diffusion coefficient and the interconnecting pore resistivity can be expressed as

$$
D_{\mathrm{Cl}^{-}}=\frac{a R T}{1.64 F^{2} R_{\mathrm{CCP}} C_{\mathrm{Cl}^{-}}} .
$$

In (9), the influences of other ions on chloride ion diffusion coefficient determination have been largely removed. To further eliminate these effects, some pastes (water-binder ratio $=10$ ) were prepared, and the cementitious material that was used is as follows: fly ash + Portland cement (cement replacement level is $20 \%, 40 \%$, and $60 \%$, resp.), slag + Portland cement (cement replacement level is $25 \%, 50 \%$, and $75 \%$, resp.), and silicon fume + Portland cement (cement replacement level is $5 \%, 10 \%$, and $15 \%$, resp.). The chemical compositions of cement and mineral admixtures are listed in Table 1.

A conductivity cell with a length of $6.92 \mathrm{~cm}$ and an electrode area of $9.62 \mathrm{~cm}^{2}$ was also made. This experiment aims to investigate the influence of different pore solutions caused by different cementitious materials used on conductance. Strictly speaking, to carry out pore solution conductivity tests, the pore solution should be squeezed out of the concrete block. However, given the complexity of the required equipment and the limited amount of the extracted pore solution, this research adopted the simulation approach by measuring high water-binder ratio paste that was prepared by using various cementitious materials. Before the age of $7 \mathrm{~d}$, the paste will not solidify by shaking the container several times every day. The paste solution was shaken for 5 minutes the day before the test and then left undisturbed for $24 \mathrm{~h}$. Then, the upper solution was taken and injected into the conductivity testing cell. The frequency of the alternating current is $2000 \mathrm{~Hz}$, and the test ages are 28 and $90 \mathrm{~d}$. Figure 6 shows the test results.

Figure 6 shows that the addition of mineral admixtures reduces the concrete pore solution conductivity. As generally accepted, the most important factor that influences permeability is connected porosity rather than pore solution conductivity. To further eliminate the influence of other ions on AC impedance testing for chloride ion diffusion coefficient determination, a correction factor can be introduced. To perform this step, the correction factor of ordinary Portland cement concrete can be set as a benchmark. For concrete that uses other cementitious materials, the correction factor may be determined by interpolation in accordance with Table 2 .

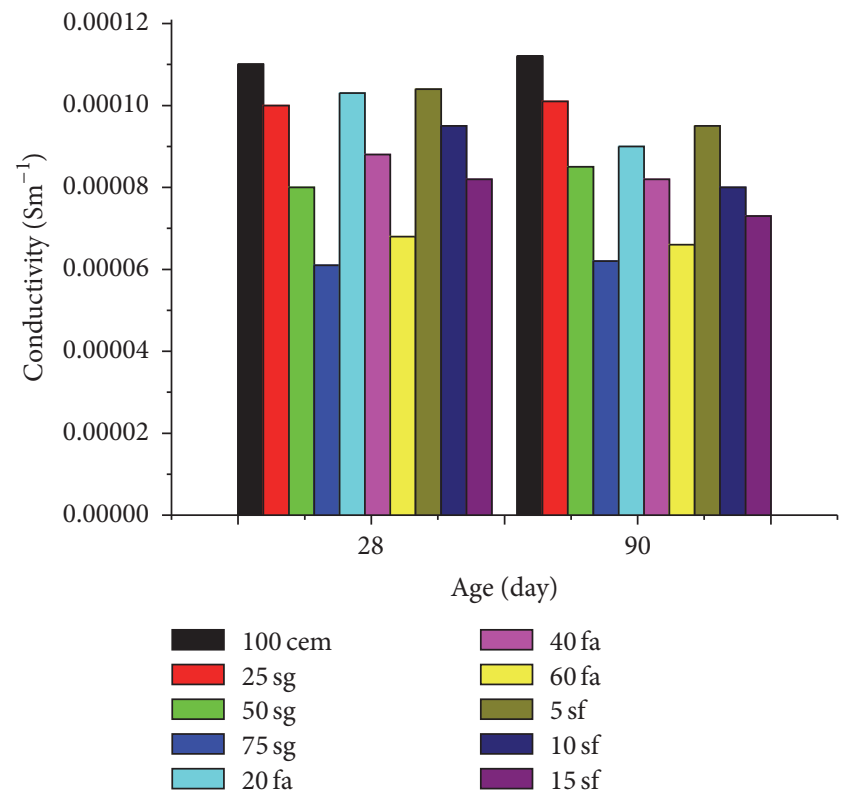

FIGURE 6: Conductivity value of different paste solutions.

TABLE 2: Diffusion coefficient correction factor.

\begin{tabular}{lccr}
\hline $\begin{array}{l}\text { Types of mineral } \\
\text { admixtures }\end{array}$ & \multicolumn{3}{c}{$\begin{array}{c}\text { (Replacement ratio)/diffusion coefficient } \\
\text { correction factor }\end{array}$} \\
\hline Fly ash & $(20 \%) 1.2$ & $(40 \%) 1.3$ & $(60 \%) 1.7$ \\
Slag & $(25 \%) 1.1$ & $(50 \%) 1.3$ & $(75 \%) 1.8$ \\
Silicon fume & $(5 \%) 1.1$ & $(10 \%) 1.3$ & $(15 \%) 1.4$ \\
\hline
\end{tabular}

\section{Experimental Studies}

Table 3 shows the concrete mix that was used in the experiment.

First, $\Phi 100 \mathrm{~mm} \times 300 \mathrm{~mm}$ cylinder test blocks were prepared for the experiment. Steel mold was removed one day after pouring, and then concrete cylinders were cured for 28 or $90 \mathrm{~d}$ before being cut into $\Phi 100 \mathrm{~mm} \times 50 \mathrm{~mm}$ blocks for vacuum saturation (using $1 \mathrm{~mol} / \mathrm{L} \mathrm{NaCl}$ solution, the saturating regime is the same as that of ASTM C1202).

Then, a $100 \mathrm{~mm} \times 100 \mathrm{~mm}$ stainless steel plate was adopted as the electrode. To ensure close contact between the electrodes and the concrete surface, soaked filter papers (using $1 \mathrm{~mol} / \mathrm{L} \mathrm{NaOH}$ solution) were introduced. Prepressure was applied to the electrodes by using screw caps. Agilent $4294 \mathrm{~A}$ precision impedance analyzer was employed (see Figure 10), and the test frequency is $40 \mathrm{~Hz}$ to $40 \mathrm{MHz}$. Five 
TABle 3: Concrete mix.

\begin{tabular}{|c|c|c|c|c|c|c|c|}
\hline \multirow{2}{*}{ Specimen number } & \multicolumn{7}{|c|}{ Materials used (unit: $\mathrm{kg} / \mathrm{m}^{3}$ ) } \\
\hline & Cement & Fly ash & Slag & Silicon fume & Water & Fine aggr. & Coarse aggr. \\
\hline $\mathrm{C} 0$ & 466.0 & 0 & 0 & 0 & 186.0 & 750.0 & 1125.0 \\
\hline FA1 & 372.8 & 92.3 & 0 & 0 & 186.0 & 735.7 & 1103.6 \\
\hline FA2 & 276.6 & 186.4 & 0 & 0 & 186.0 & 720.5 & 1080.9 \\
\hline FA3 & 186.4 & 276.6 & 0 & 0 & 186.0 & 705.3 & 1058.0 \\
\hline GS1 & 349.5 & 0 & 116.5 & 0 & 186.0 & 747.6 & 1121.4 \\
\hline GS2 & 233.0 & 0 & 233.0 & 0 & 186.0 & 744.2 & 1116.3 \\
\hline GS3 & 116.5 & 0 & 349.5 & 0 & 186.0 & 740.8 & 1111.2 \\
\hline SF1 & 442.7 & 0 & 0 & 23.3 & 186.0 & 747.6 & 1121.4 \\
\hline SF2 & 419.4 & 0 & 0 & 46.6 & 186.0 & 744.2 & 1116.3 \\
\hline SF3 & 396.1 & 0 & 0 & 69.9 & 186.0 & 740.8 & 1111.2 \\
\hline JH1 & 266.0 & 114.0 & 0 & 0 & 144.0 & 760.8 & 1141.2 \\
\hline JH2 & 190.0 & 95.0 & 95.0 & 0 & 144.0 & 761.2 & 1141.8 \\
\hline JH3 & 195.0 & 130.0 & 65.0 & 0 & 144.0 & 752.8 & 1129.2 \\
\hline
\end{tabular}

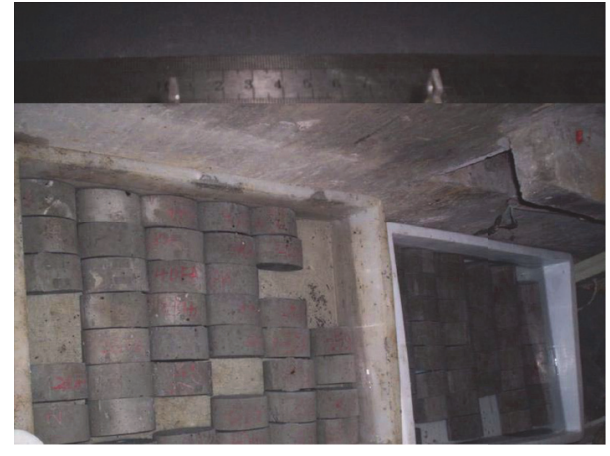

Figure 7: Concrete blocks for the impedance test.

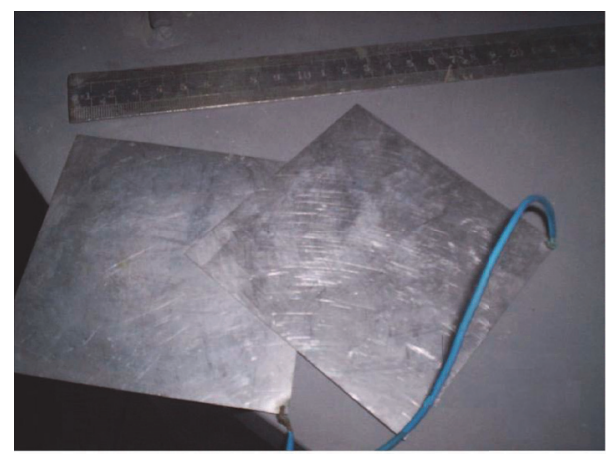

FIgURE 8: Stainless steel electrodes.

test points were measured for each order of magnitude. The test block, electrode, electrode installation, and impedance analyzer are shown in Figures 7-9, respectively.

Figure 11 shows the AC impedance spectroscopy test result of the C0 test block ( $90 \mathrm{~d}$ ).

To verify the validity of the measured impedance data, a validation check by using linear Kramers-Kronig test [10]

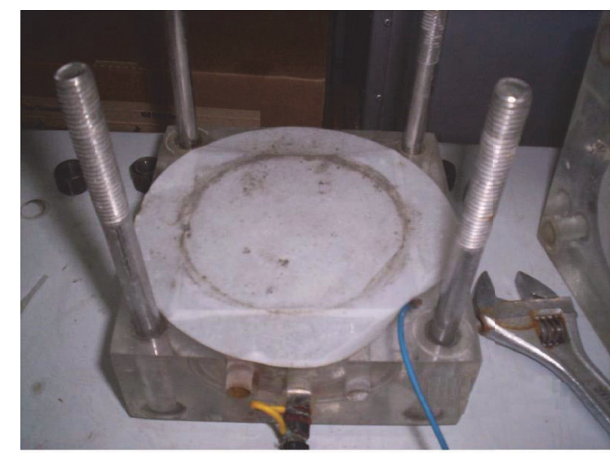

FIGURE 9: Electrode mounting.

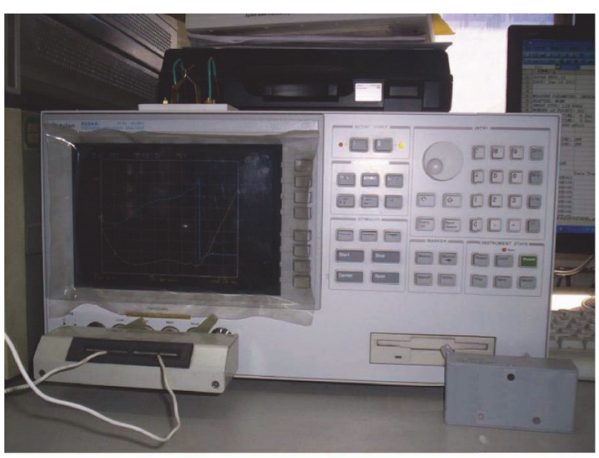

FIGURE 10: Impedance tester.

was conducted. Figure 12 shows the validation results of typical ordinary Portland cement concrete, cement + fly ash composite binder concrete, cement + slag composite binder concrete, and cement + silica fume composite binder concrete.

In Figure 12, the abscissa axis represents the frequency, and the ordinate axis on both sides represents the residuals 


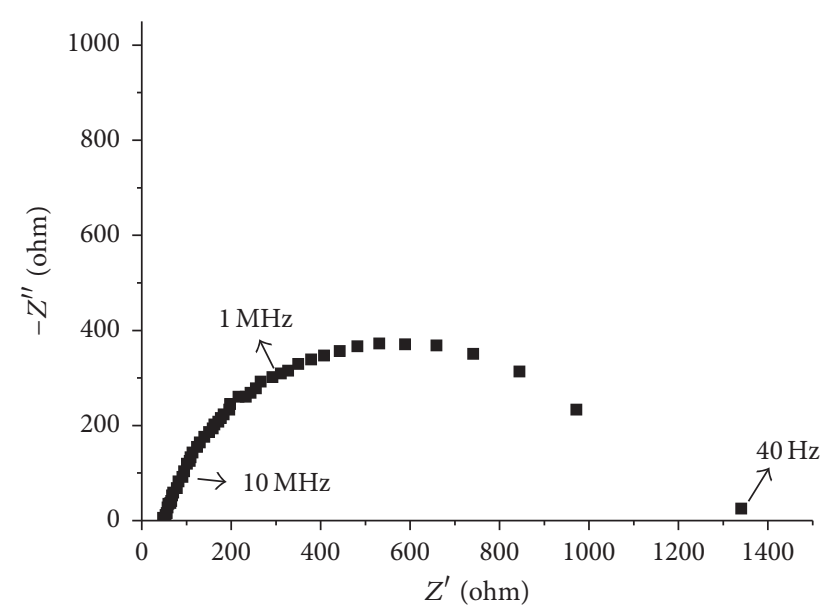

FIGURE 11: Nyquist plot of spectroscopy test results of specimen number C0.

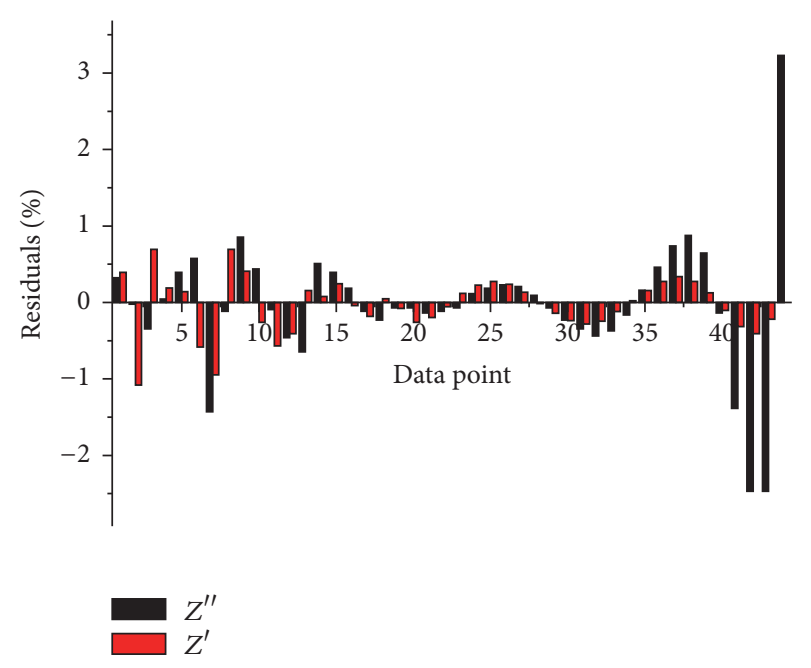

(a) Specimen number C0,90 d

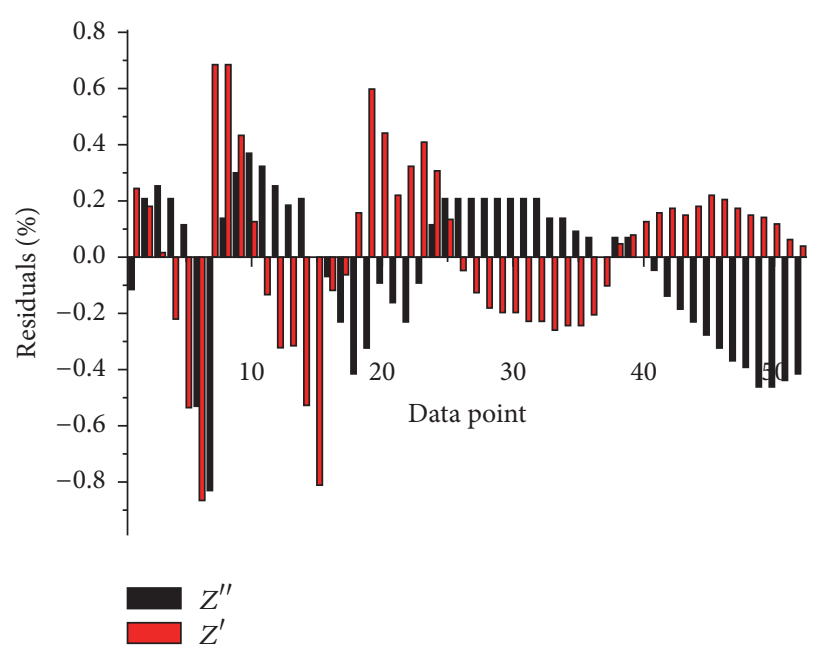

(c) Specimen number GS2, $90 \mathrm{~d}$

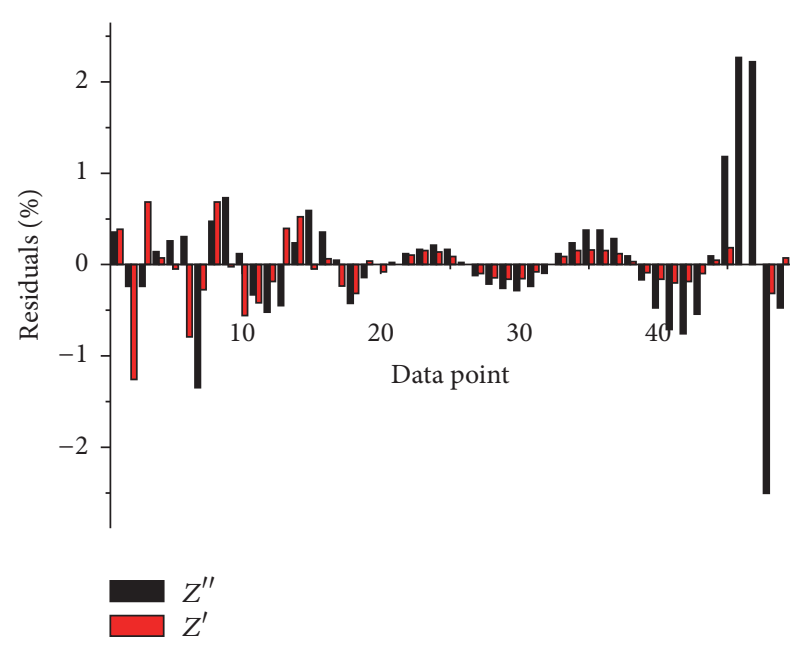

(b) Specimen number FA2, $90 \mathrm{~d}$

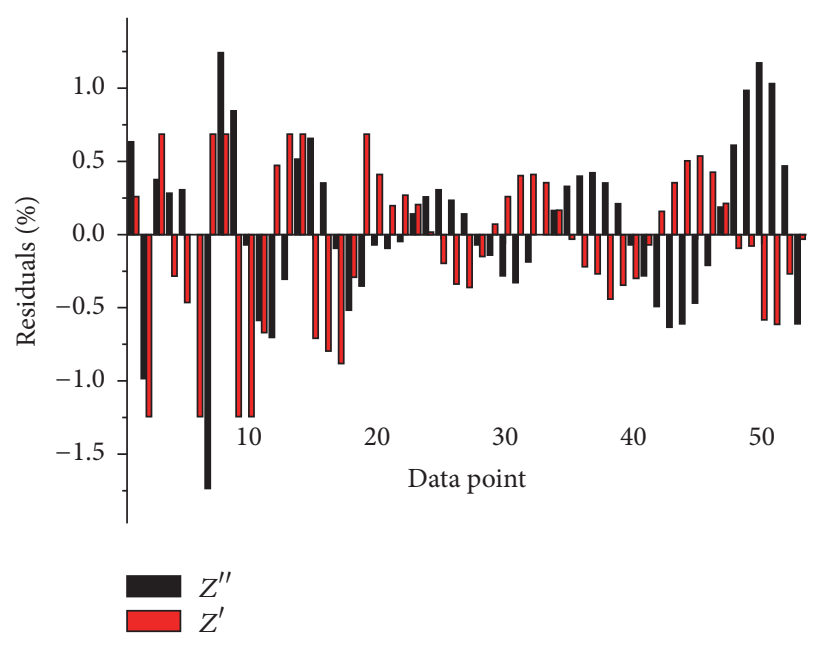

(d) Specimen number SF2, $90 \mathrm{~d}$

FIGURE 12: Validation results. 
of Voigt model fitting. Equation (10) is used to calculate the residuals:

$$
\begin{aligned}
& \text { Residuals }(\operatorname{Re} Z)=\frac{\left(Z_{\mathrm{Re}}-Z_{\mathrm{Re}-\mathrm{cal}}\right)^{2}}{Z_{\mathrm{Re}}^{2}}, \\
& \text { Residuals }(\operatorname{Im} Z)=\frac{\left(Z_{\mathrm{Im}}-Z_{\mathrm{Im}-\mathrm{cal}}\right)^{2}}{Z_{\mathrm{Im}}^{2}},
\end{aligned}
$$

where $Z_{\mathrm{Re}}$ and $Z_{\mathrm{Im}}$ are real part and the imaginary part of the measured impedance, respectively, and $Z_{\text {Re-cal }}$ and $Z_{\text {Im-cal }}$ are the fitted values obtained by using the Voigt model. Small residuals correspond to better validity.

Only measured data that passed the Kramers-Kronig test can be used for further numerical fitting. Figure 12 shows that the obtained impedance data shows good validity, which can be attributed to the measures employed in this section. Moreover, the repeatability of the test data is good because of reliable close contact between the test block and the electrodes.

Parameters $R_{0}, R_{1}$, and $C_{1}$ can be obtained through numerical fitting of the measured impedance data and the preset equivalent circuit shown in Figure 5. The chloride ion diffusion coefficient can be calculated by using $R_{\mathrm{CCP}}=R_{0}+R_{1}$ and (9).

The method of determining chloride ion diffusion coefficient based on the AC impedance technique is performed as follows:

(1) Prepare $\Phi 100 \mathrm{~mm} \times 50 \mathrm{~mm}$ specimens and conduct vacuum $\mathrm{Cl}^{-}$saturating using $1 \mathrm{~mol} / \mathrm{L} \mathrm{NaCl}$ solution (the saturating regime is the same as that of ASTM C1202).

(2) Carry out AC impedance testing to obtain impedance spectroscopy data.

(3) Perform data validation.

(4) Obtain $R_{\mathrm{CCP}}$ from equivalent circuit fitting.

(5) Calculate chloride ion diffusion coefficient using (9).

(6) Modify the diffusion coefficient according to the cementitious material that was used.

The rapid chloride permeability test ASTM C1202 has been adopted as national standard by many countries, including China, the United States, and Canada. The ASTM C1202 method specifies the rating of chloride permeability of concrete based on the charge passed through the specimen during $6 \mathrm{~h}$ of testing period. ASTM C1202 tests that use the same concrete blocks were conducted to perform a comparison. Figure 13 shows the relationship between chloride ion diffusion coefficients obtained from impedance-based technology and $6 \mathrm{~h}$ electric flux. A linear correlation $\left(Q_{\mathrm{C} 1202}=\right.$ $930 \times D_{\mathrm{Cl}^{-}}$,) between the rapid chloride permeability test and the proposed method was obtained, with a correlation coefficient of 0.9; see Figure 13 for details.

As can be seen from Figure 13, some data points deviate from the straight line. As reported by Shi [11], the ASTM C1202 method is virtually a measurement of electrical conductivity of concrete, which depends on both the pore

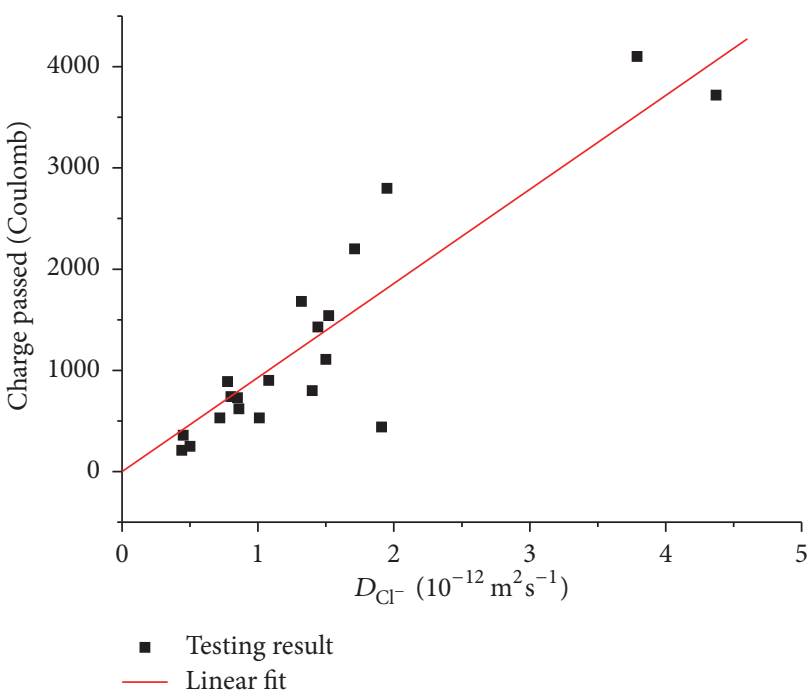

FIGURE 13: Relationship between chloride ion diffusion coefficient using ACIS and 6 h electric flux from ASTM C1202 tests.

structure characteristics and pore solution chemistry of concrete. Supplementary cementing materials such as silica fume, fly ash, and ground blast furnace slag may have a significant effect on the chemistry or electrical conductivity of pore solution, depending on the alkali content of the supplementary cementing material, replacement level, and age, which has little to do with the chloride permeability. ASTM C1202 method is susceptible to pore solution conductance. However, the proposed method eliminates the effect of pore solution conductivity on permeability by using a carefully designed technique. This effect may be an important reason for the moderate correlation between the two methods.

\section{Conclusions}

(1) High-frequency AC impedance spectroscopy can reflect the mesostructural properties of materials, which enables us to indirectly study the permeability of concrete. An equivalent circuit model with a clear physical meaning was adopted through an investigation of AC conduction paths in concrete. Through numerical fitting of the Nyquist plot of the measured impedance spectroscopy and a preset model, a parameter that characterizes diffusion resistance that depends on the interconnected porosity and pore solution conductivity was obtained. Based on the Einstein-Smoluchowski equation, the chloride ion diffusion coefficient was derived, and the proposed formula was modified to eliminate the influence of pore solution conductivity on diffusion coefficient measurement. Then, an accurate formula that reflects chloride ion diffusion resistance was obtained.

(2) With test block size, specimen pretreatment, impedance test parameters, equivalent circuit selection, and diffusion coefficient formula modification taken into consideration, a method of determining the chloride ion diffusion coefficient based on AC impedance spectroscopy was established. In addition, the test procedure was summarized for practical purposes. 
(3) The relationship between the proposed method and the traditional ASTM C1202 method was established. Results showed that a certain but not very high degree of linear correlation exists, which can be attributed to the fact that ASTM C1202 method is essentially a conductance method influenced by pore solution conductivity, whereas pore solution conductivity has little effect compared with interconnected porosity on chloride ion diffusion behavior in concrete.

\section{Competing Interests}

The authors declare that there is no conflict of interests regarding the publication of this paper.

\section{Acknowledgments}

The authors acknowledge the support from National Natural Science Foundation of China (Grant nos. 51408379 and 51508350) and Natural Science Foundation of Hebei, China (Grant no. E2013210125).

\section{References}

[1] L. Kong and Y. Du, "Effect of lightweight aggregate and the interfacial transition zone on the durability of concrete based on grey correlation," Indian Journal of Engineering and Materials Sciences, vol. 22, no. 1, pp. 111-119, 2015.

[2] A. E. Long, G. D. Henderson, and F. R. Montgomery, "Why assess the properties of near-surface concrete?" Construction and Building Materials, vol. 15, no. 2-3, pp. 65-79, 2001.

[3] M. Cabeza, M. Keddam, X. R. Nóvoa, I. Sánchez, and H. Takenouti, "Impedance spectroscopy to characterize the pore structure during the hardening process of Portland cement paste," Electrochimica Acta, vol. 51, no. 8-9, pp. 1831-1841, 2006.

[4] G. Dotelli and C. M. Mari, "The evolution of cement paste hydration process by impedance spectroscopy," Materials Science and Engineering A, vol. 303, no. 1-2, pp. 54-59, 2001.

[5] M. Cabeza, P. Merino, X. R. Nóvoa, and I. Sánchez, "Electrical effects generated by mechanical loading of hardened Portland cement paste," Cement and Concrete Composites, vol. 25, no. 3, pp. 351-356, 2003.

[6] P. Gu, P. Xie, J. J. Beaudoin, and R. Brousseau, "A.C. impedance spectroscopy (I): a new equivalent circuit model for hydrated portland cement paste," Cement and Concrete Research, vol. 22, no. 5, pp. 833-840, 1992.

[7] G. Song, "Equivalent circuit model for AC electrochemical impedance spectroscopy of concrete," Cement and Concrete Research, vol. 30, no. 11, pp. 1723-1730, 2000.

[8] M. Shi, Z. Chen, and J. Sun, "Determination of chloride diffusivity in concrete by AC impedance spectroscopy," Cement and Concrete Research, vol. 29, no. 7, pp. 1111-1115, 1999.

[9] C. Andrade, "Calculation of chloride diffusion coefficients in concrete from ionic migration measurements," Cement and Concrete Research, vol. 23, no. 3, pp. 724-742, 1993.

[10] J. M. Esteban and M. E. Orazem, "On the application of the Kramers-Kronig relations to evaluate the consistency of electrochemical impedance data," Journal of the Electrochemical Society, vol. 138, no. 1, pp. 67-76, 1991.

[11] C. Shi, "Effect of mixing proportions of concrete on its electrical conductivity and the rapid chloride permeability test
(ASTM C1202 or ASSHTO T277) results," Cement and Concrete Research, vol. 34, no. 3, pp. 537-545, 2004. 


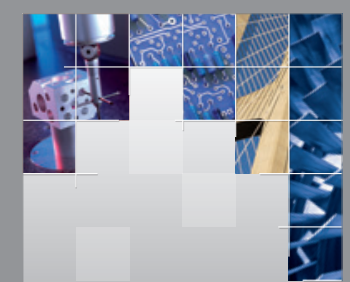

\section{Enfincering}
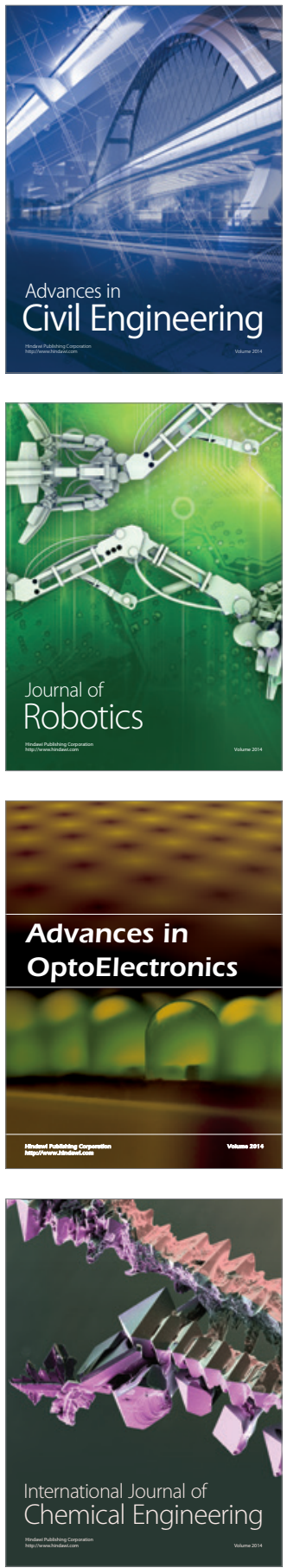

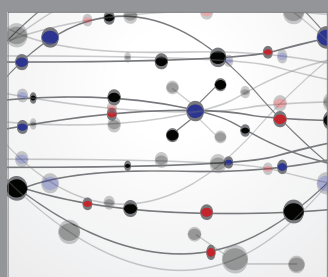

The Scientific World Journal

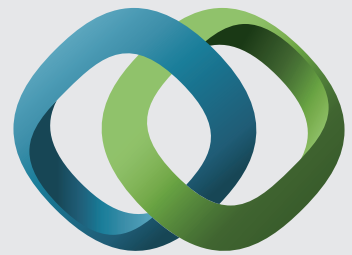

\section{Hindawi}

Submit your manuscripts at

http://www.hindawi.com
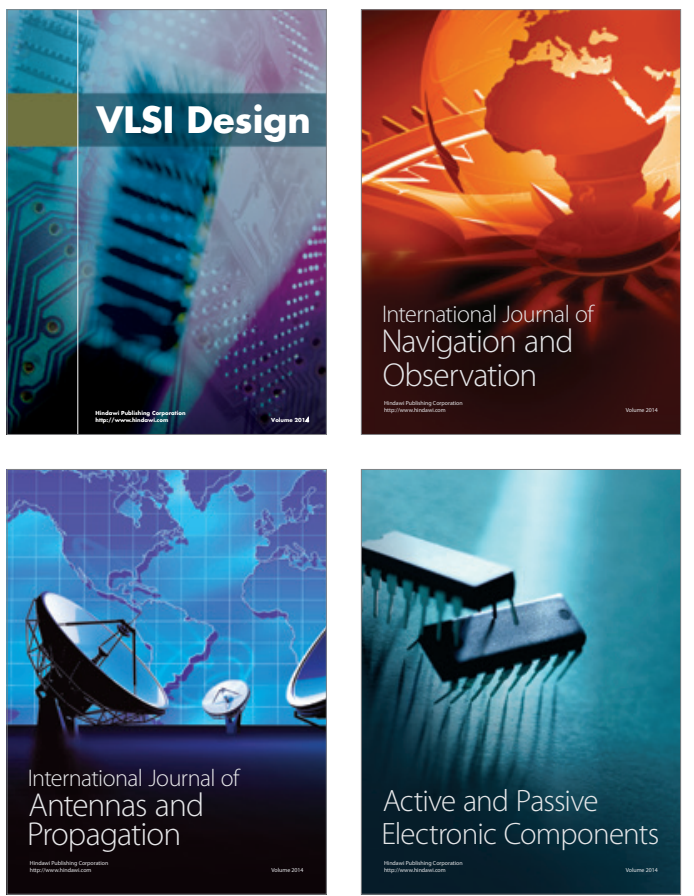
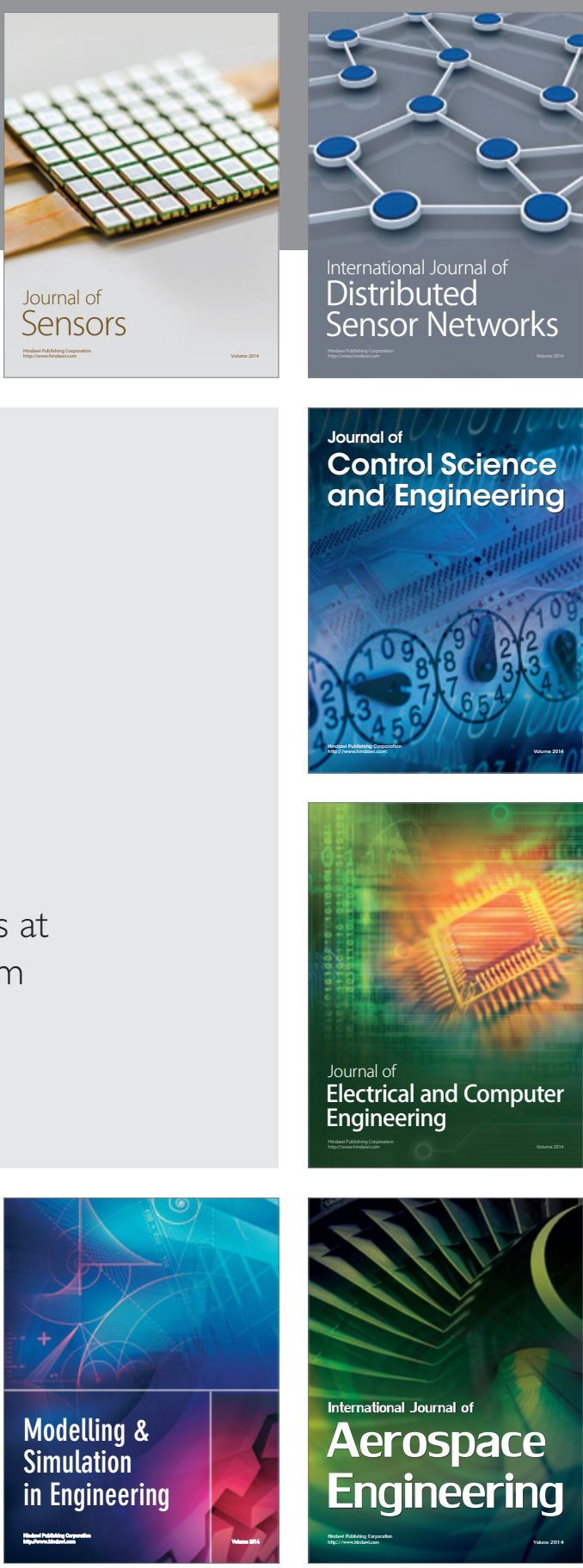

International Journal of

Distributed

Sensor Networks

Journal of

Control Science

and Engineering
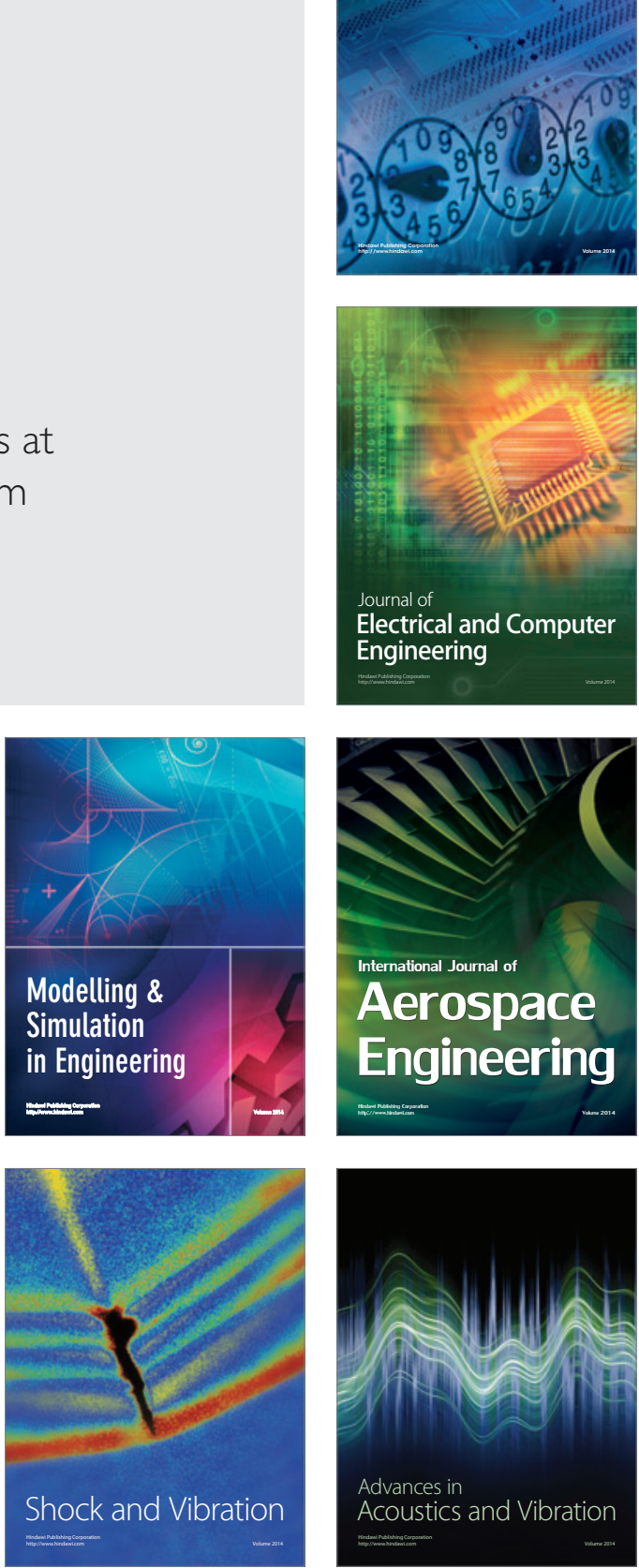